\title{
Cold crystallization and molecular structure of imidazolium-based ionic liquid crystals with a p-nitroazobenzene moiety
}

Katsuma Ishino, ${ }^{1}$ Hajime Shingai, ${ }^{1}$ Yasuyuki Hikita, ${ }^{1}$ Isao Yoshikawa, ${ }^{2}$ Hirohiko

Houjou,,$^{2,3}$ and Katsunori Iwase, ${ }^{1,4 *}$

${ }^{1}$ DENSO CORPORATION, 500-1 Minamiyama, Komenoki-cho, Nisshin, Aichi

470-0111, JAPAN

2 Institute of Industrial Science, The University of Tokyo, 4-6-1 Komaba, Meguro-ku, Tokyo 153-8505, JAPAN

${ }^{3}$ Environmental Science Center, The University of Tokyo, 7-3-1 Hongo, Bunkyo-ku, Tokyo 113-0033, JAPAN

${ }^{4}$ Institute of Materials and Systems for Sustainability, Nagoya University, Furo-cho, Chikusa-ku, Nagoya, Aichi 464-8601, JAPAN 
KEYWORDS: cold crystallization, ionic liquid crystals, thermal analysis, ONIOM calculation 


\section{Contents:}

\section{Packing structure}

Figure S1. Packing structure viewed along the crystallographic $a$-axis and $b$-axis: $a$-axis (A) and $b$-axis (B) in $\alpha$-Cr and $a$-axis (C) and $b$-axis (D) in $\beta$-Cr. The dotted lines represent the unit cell. The SS-form molecule in $\beta$-Cr, C15 was disordered (Figure 1 (B), light), where $\sim 83 \%$ of the cations in the crystal corresponded to this structure with the remaining $\sim 17 \%$ exhibiting the $\mathrm{C} 15^{\prime}$ conformation relative to $\mathrm{C} 15$. The main conformation of this cation is shown in Figure $\mathrm{S} 1(\mathrm{~A})$ and (B).

\section{XRD-DSC analyses}

Figure S2. XRD-DSC results of 1-Bf (A) obtained during the second heating compared with the calculated pattern, (B) based on the initial crystal structure determined independently. Left, $\mathrm{XRD}\left(5 \leq 2 \theta /^{\circ} \leq 35\right)$; right, DSC (black line, temperature; red line, heat flow).

\section{DSC analyses}

Figure S3. DSC traces of the 1-Bf at a scanning rate of $\pm 5.0{ }^{\circ} \mathrm{C} \mathrm{min}-1$, where fusion is denoted by $T_{\mathrm{m} 1-1}$, $T_{\mathrm{m} 1-2}, T_{\mathrm{m} 2-1}$, and $T_{\mathrm{m} 2-2}$, cold crystallization by $T_{\mathrm{cc}}$, and crystallization by $T_{\mathrm{c} 1-1}, T_{\mathrm{c} 1-2}, T_{\mathrm{c} 2-1}$, and $T_{\mathrm{c} 2-2}$. The starting sample was Sample-II $(\beta-\mathrm{Cr})$.

Figure S4. DSC thermograms of non-isothermal cold crystallization process in 1-Bf at different heating rates $\left(3{ }^{\circ} \mathrm{C} \min ^{-1} \sim 50{ }^{\circ} \mathrm{C} \mathrm{min}^{-1}\right)$ under constant cooling rate $\left(5^{\circ} \mathrm{C} \mathrm{min}^{-1}: \mathrm{i}\right)$. The heating scan rates of $3{ }^{\circ} \mathrm{C} \mathrm{min}-1$ (ii), $5{ }^{\circ} \mathrm{C} \mathrm{min}^{-1}$ (iii), $10{ }^{\circ} \mathrm{C} \mathrm{min}^{-1}$ (iv), $15{ }^{\circ} \mathrm{C} \mathrm{min}^{-1}$ (v), $20{ }^{\circ} \mathrm{C} \mathrm{min}^{-1}$ (vi), and $50{ }^{\circ} \mathrm{C} \min ^{-1}$ (vii).

Table S1. Thermodynamic characteristics of crystallization $\left(T_{\mathrm{c}}\right)$, cold crystallization ( $\left.T_{\mathrm{cc}}\right)$, and Fusion ( $\left.T_{\mathrm{m}}\right)$ at a scanning rate of $\pm 5^{\circ} \mathrm{C} \mathrm{min}^{-1}$. The starting sample was Sample-I $(\alpha$ - $\mathrm{Cr})$.

\section{Small-Angle X-ray Scattering (SAXS).}

Figure S5. Variation in the small angle X-ray scattering (SAXS) of 1-Bf during the cold crystallization in the second heating process. The $2 \theta$ value are those for $\lambda$ of $\mathrm{Cu} \mathrm{K} \alpha$ radiation.

\section{Nuclear Magnetic Resonance (NMR)}

Figure S6. ${ }^{1} \mathrm{H}$ NMR Spectrum of 1-Bf.

Figure S7. ${ }^{13} \mathrm{C}$ NMR Spectrum of 1-Bf.

\section{MALDI - Time-of-flight mass spectroscopy (TOF-MS)}


Figure S8. MALDI-TOF MS Spectrum of 1-Bf.

\section{Quantum-Chemical calculations}

Table S2. Atomic Cartesian coordinates of the L-form molecules in $\alpha$-Cr was fully optimized using ONIOM with the center and the peripheral molecules at the B3LYP/6-311G** and the HF/6-31G levels, respectively.

Table S3. Atomic Cartesian coordinates of the L-form molecules in $\beta$-Cr was fully optimized using ONIOM with the center and the peripheral molecules at the B3LYP/6-311G** and the HF/6-31G levels, respectively.

Table S4. Energy calculation results. 
(A)

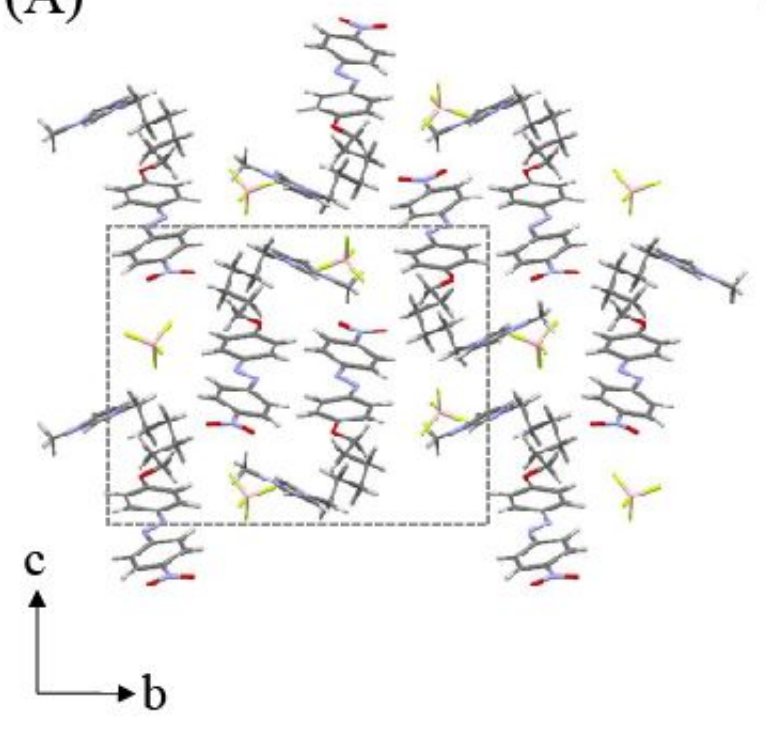

(B)

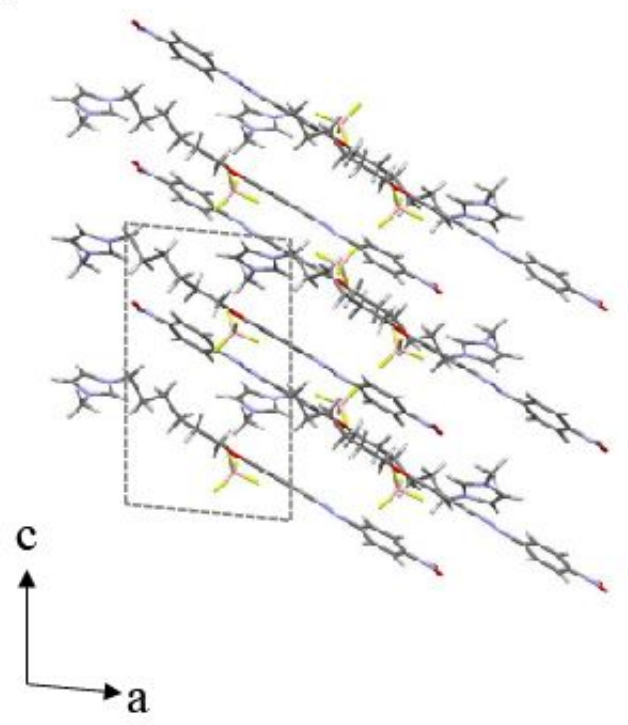

(C)

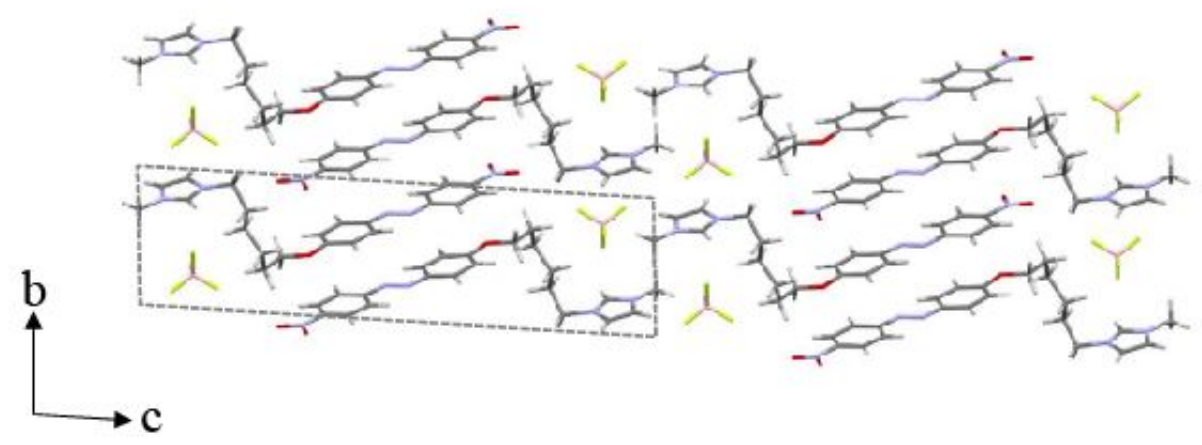

(D)

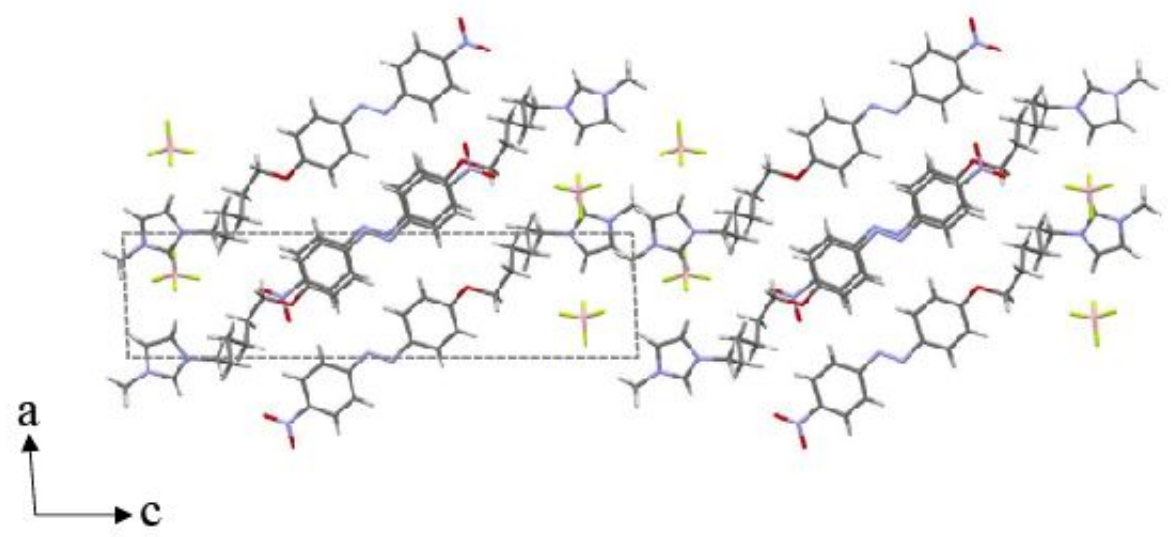

Figure S1. Packing structure viewed along the crystallographic $a$-axis and $b$-axis: $a$-axis (A) and $b$-axis (B) in $\alpha$-Cr and $a$-axis (C) and $b$-axis (D) in $\beta$-Cr. The dotted line represents the unit cell. The SS-form molecule in $\beta-\mathrm{Cr}, \mathrm{C} 15$ was disordered (Figure 1 (B), light), where $\sim 83 \%$ of the cations in the crystal corresponded to this structure with the remaining $\sim 17 \%$ exhibiting the $\mathrm{C} 15$ ' conformation relative to $\mathrm{C} 15$. The main conformation of this cation is shown in Figure S1(A) and (B). 


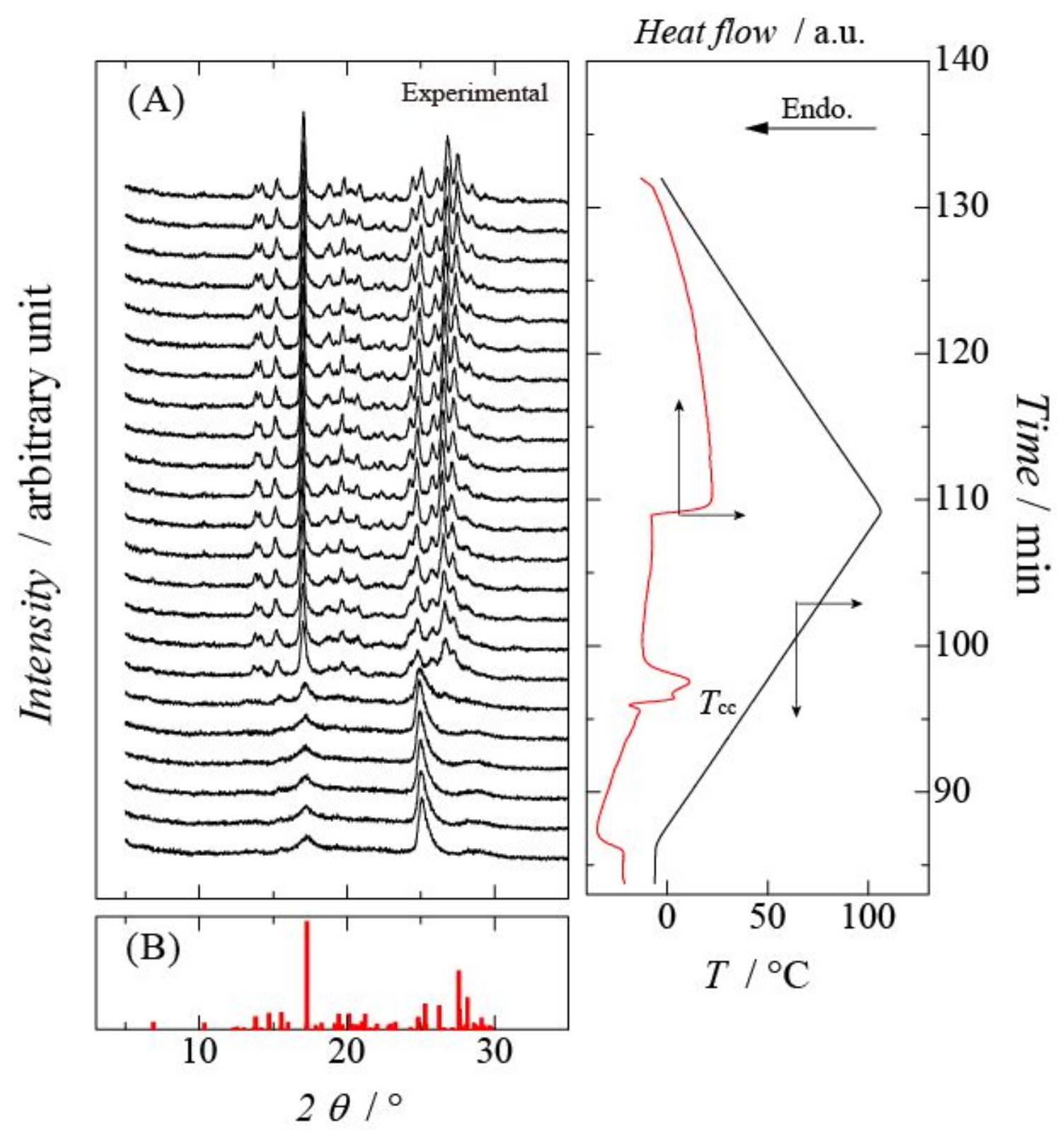

Figure S2. XRD-DSC results of 1-Bf (A) obtained during the second heating compared with the calculated pattern, (B) based on the initial crystal structure determined independently. Left, XRD ( $5 \leq 2 \theta$ $1^{\circ} \leq 35$ ); right, DSC (black line, temperature; red line, heat flow). 


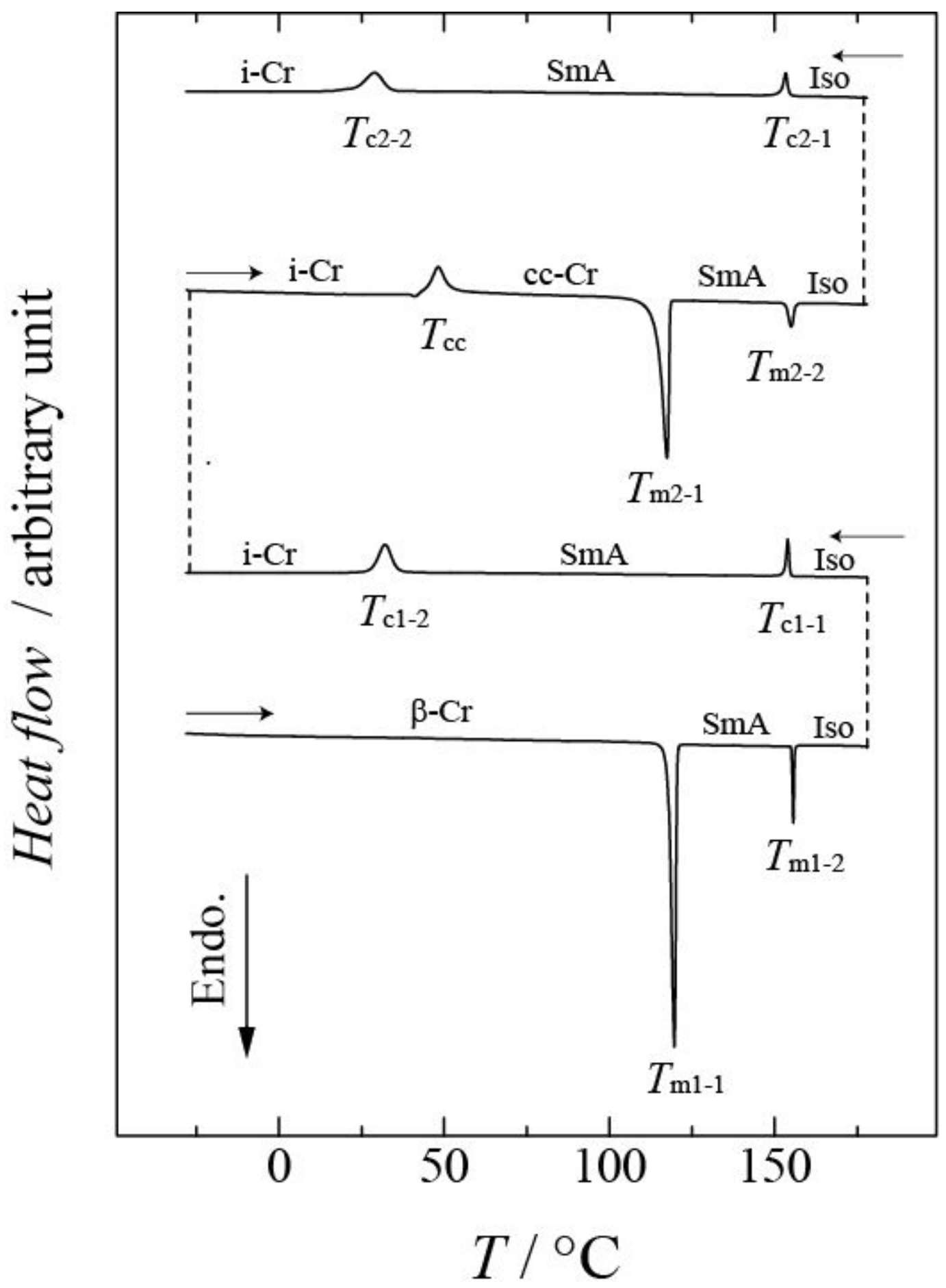

Figure S3. DSC traces of the 1-Bf at a scanning rate of $\pm 5.0^{\circ} \mathrm{C} \mathrm{min}-1$, where fusion is denoted by $T_{\mathrm{m} 1-1}$, $T_{\mathrm{m} 1-2}, T_{\mathrm{m} 2-1}$, and $T_{\mathrm{m} 2-2}$, cold crystallization by $T_{\mathrm{cc}}$, and crystallization by $T_{\mathrm{c} 1-1}, T_{\mathrm{c} 1-2}, T_{\mathrm{c} 2-1}$, and $T_{\mathrm{c} 2-2}$. The starting sample was Sample-II $(\beta-\mathrm{Cr})$. 


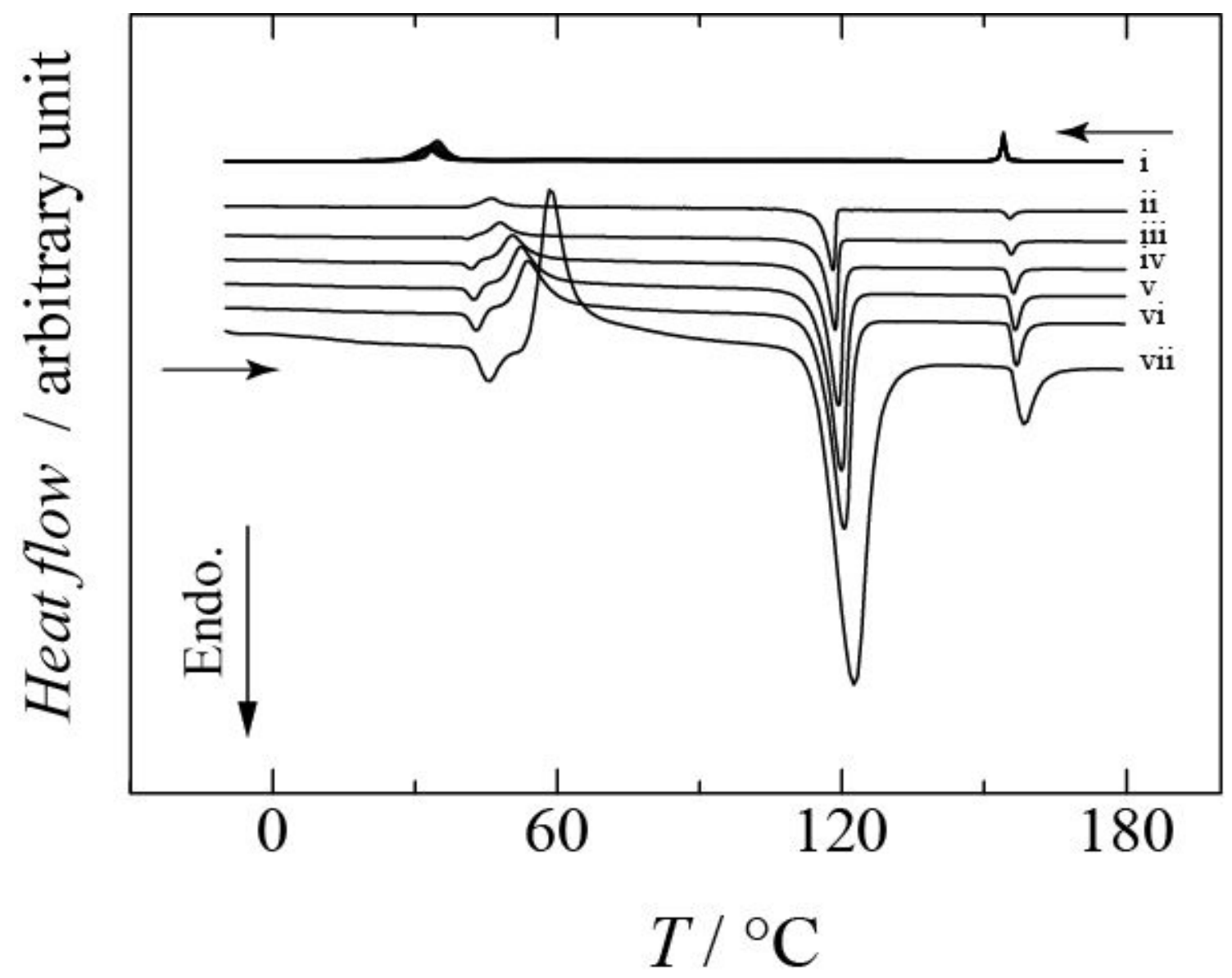

Figure S4. DSC thermograms of non-isothermal cold crystallization process in 1-Bf at different heating rates $\left(3{ }^{\circ} \mathrm{C} \mathrm{min}-1150{ }^{\circ} \mathrm{C} \min ^{-1}\right)$ under constant cooling rate $\left(5^{\circ} \mathrm{C} \mathrm{min}-1\right.$ : i $)$. The heating scan rates of $3{ }^{\circ} \mathrm{C}$ $\min ^{-1}$ (ii), $5^{\circ} \mathrm{C} \mathrm{min}^{-1}$ (iii), $10{ }^{\circ} \mathrm{C} \mathrm{min}^{-1}$ (iv), $15^{\circ} \mathrm{C} \mathrm{min}^{-1}$ (v), $20{ }^{\circ} \mathrm{C} \mathrm{min}-1$ (vi), and $50{ }^{\circ} \mathrm{C} \mathrm{min}^{-1}$ (vii). 


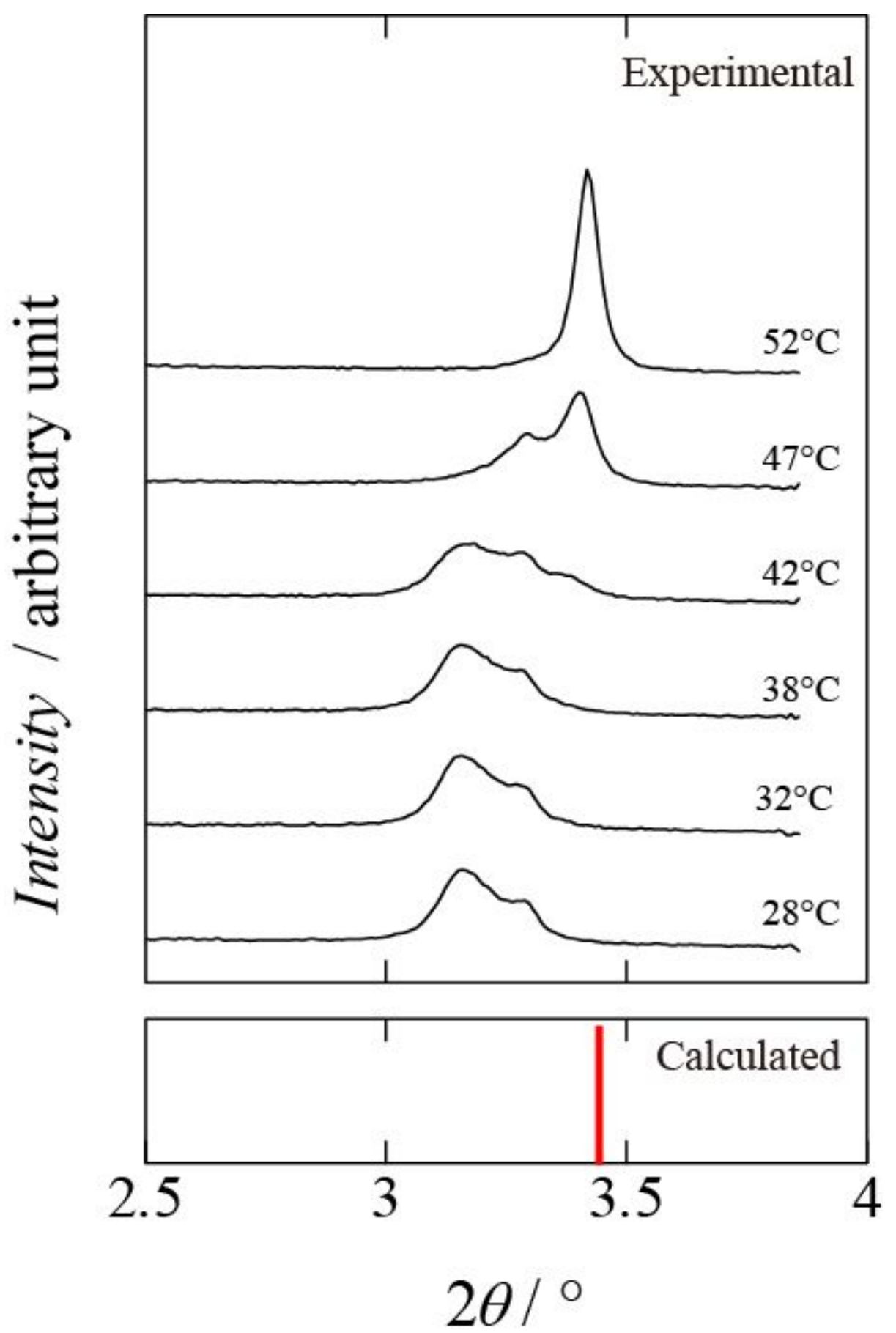

Figure S5. Variation in the small angle X-ray scattering (SAXS) of 1-Bf during the cold crystallization in the second heating process. The $2 \theta$ value are those for $\lambda$ of $\mathrm{Cu} \mathrm{K} \alpha$ radiation. 
Table S1. Thermodynamic characteristics of crystallization $\left(T_{\mathrm{c}}\right)$, cold crystallization $\left(T_{\mathrm{cc}}\right)$, and Fusion ( $\left.T_{\mathrm{m}}\right)$ at a scanning rate $\pm 5{ }^{\circ} \mathrm{C} \mathrm{min}^{-1}$. The starting sample was Sample-I $(\alpha-\mathrm{Cr})$.

Endothermal anomaly

Exothermal anomaly

\begin{tabular}{|c|c|c|c|c|c|c|}
\hline Event & $T /{ }^{\circ} \mathrm{C}$ & $\mathrm{kJ} \mathrm{mol}^{-1}$ & $\mathrm{~J} \mathrm{~K}^{-1} \mathrm{~mol}^{-1}$ & $T /{ }^{\circ} \mathrm{C}$ & $\mathrm{kJ} \mathrm{mol}^{-1}$ & $\mathrm{~J} \mathrm{~K}^{-1} \mathrm{~mol}^{-1}$ \\
\hline$T_{\mathrm{m} 1-1}$ & 123.6 & 37.7 & 95.1 & & & \\
\hline$T_{\mathrm{m} 1-2}$ & 155.1 & 3.5 & 8.2 & & & \\
\hline$T_{\mathrm{c} 1-1}$ & & & & 155.0 & 3.5 & 8.2 \\
\hline$T_{\mathrm{c} 1-2}$ & & & & 37.6 & 9.5 & 30.5 \\
\hline$T_{\mathrm{cc}}$ & & & & 42.2 & 10.8 & 34.4 \\
\hline$T_{\mathrm{m} 2-1}$ & 115.9 & 37.2 & 95.5 & & & \\
\hline$T_{\mathrm{m} 2-2}$ & 154.9 & 3.5 & 8.2 & & & \\
\hline$T_{\mathrm{c} 2-1}$ & & & & 155.3 & 3.5 & 8.1 \\
\hline$T_{\mathrm{c} 2-2}$ & & & & 37.2 & 10.3 & 33.2 \\
\hline
\end{tabular}




\section{Nuclear Magnetic Resonance (NMR)}

The sample used in this study was characterized using ${ }^{1} \mathrm{H}-$ and ${ }^{13} \mathrm{C}-\mathrm{NMR}$ (Figures S6 and S7) showing that our sample is single phase and the impurity level is considered to be insignificant, judging from non-detection of the unassignable peaks comparable to the satellite peaks ( $7.08 \mathrm{ppm}$ and $7.42 \mathrm{ppm})$ in ${ }^{1} \mathrm{H}-\mathrm{NMR}$.

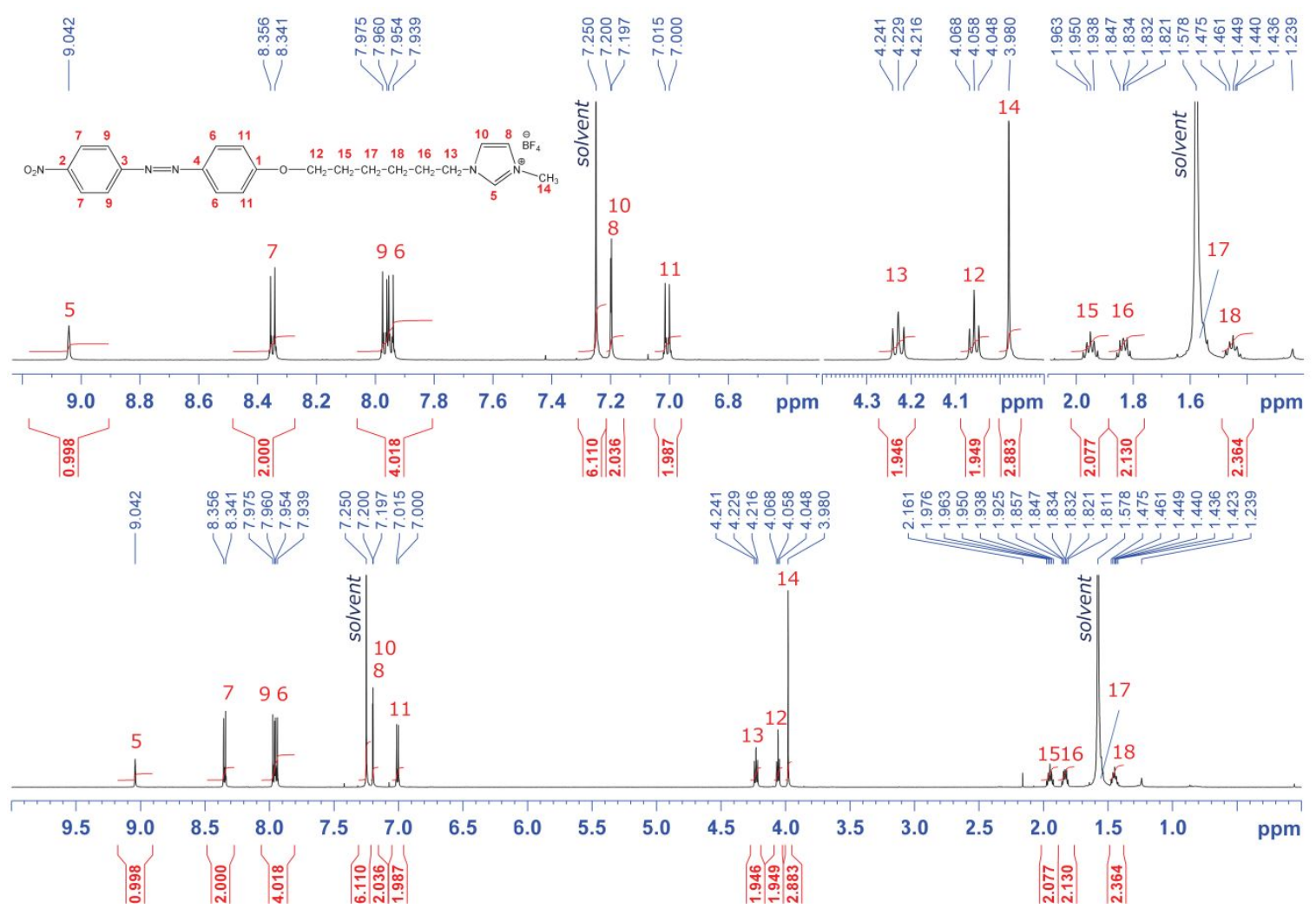

Figure S6. ${ }^{1} \mathrm{H}$ NMR Spectrum of 1-Bf. 


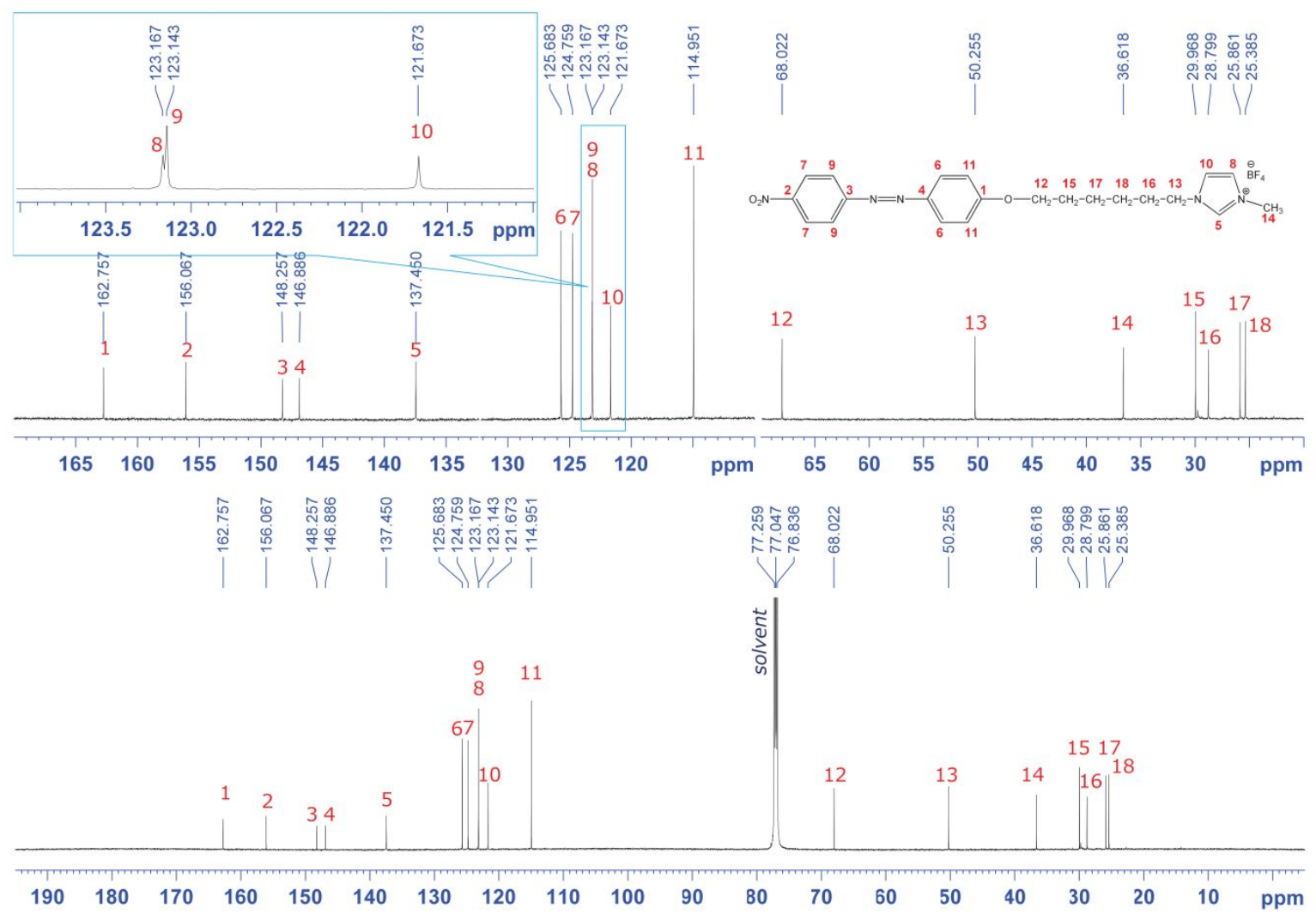

Figure S7. ${ }^{13} \mathrm{C}$ NMR Spectrum of 1-Bf. 


\section{MALDI - Time-of-flight mass spectroscopy (TOF-MS)}

We have measured time-of-flight mass spectroscopy (TOF-MS) of our sample which detected cations and anions with $\mathrm{m} / \mathrm{z}$ expected from $1-\left\{\left[4^{\prime}-\left(4{ }^{\prime}\right.\right.\right.$ '-nitrophenylazo)phenyloxy $\left.]\right\}$ hexyl-3-methyl $1 \mathrm{H}$-imidazol-3-ium tetrafluoroborate, and conclude that the impurity level is below the level of concern for this study (Figure S8).

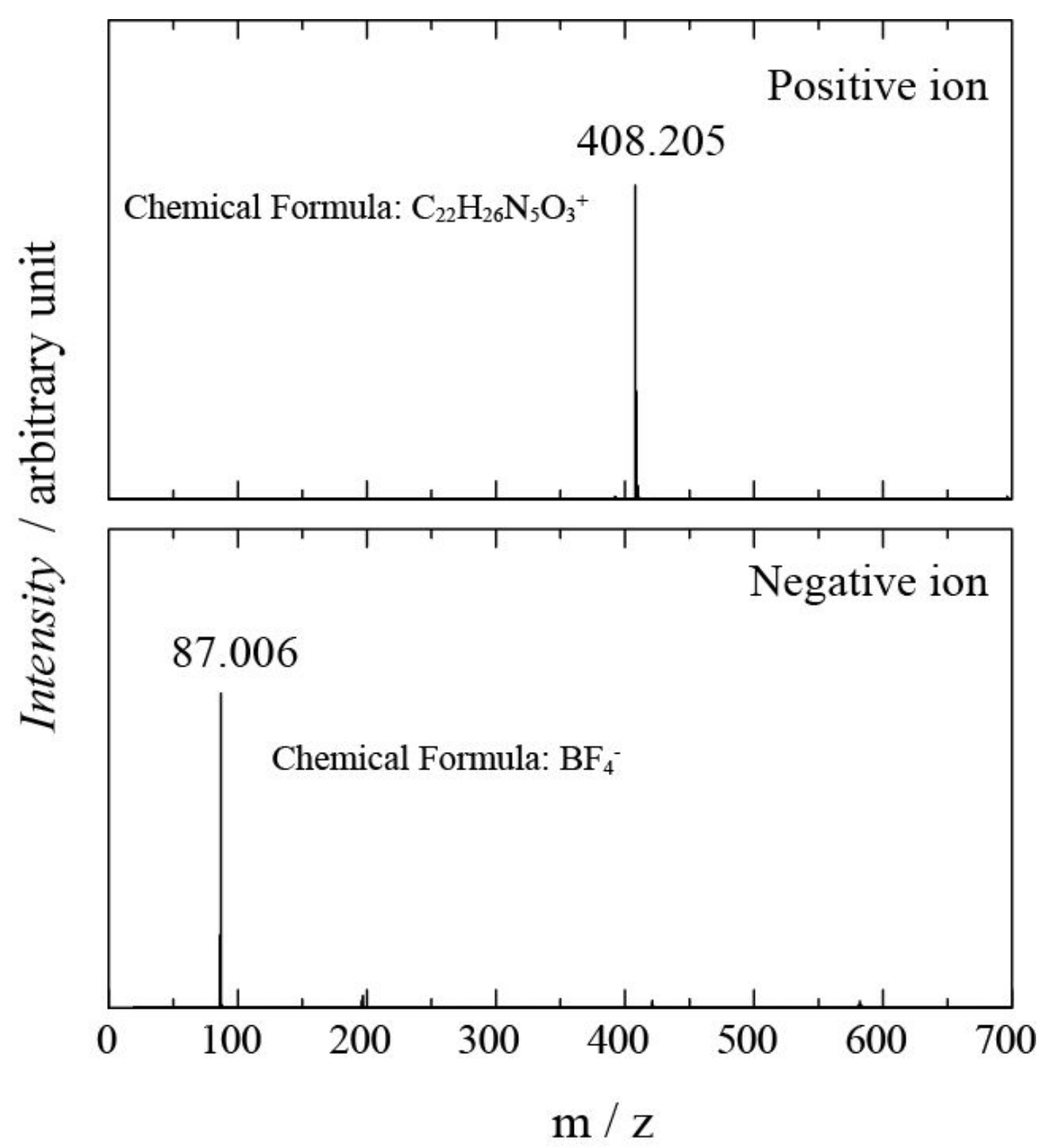

Figure S8. MALDI-TOF MS Spectrum of 1-Bf. 


\section{Quantum-chemical calculations}

Table S2. Atomic Cartesian coordinates of the L-form molecules in $\alpha$-Cr was fully optimized using ONIOM with the center and the peripheral molecules at the B3LYP/6-311G** and the HF/6-31G levels, respectively.

\begin{tabular}{|c|c|c|c|c|c|c|c|}
\hline \multirow{2}{*}{$\begin{array}{l}\text { Atomic } \\
\text { Number }\end{array}$} & \multicolumn{3}{|c|}{ Coordinates $(\AA)$} & \multirow{2}{*}{$\begin{array}{l}\text { Atomic } \\
\text { Number }\end{array}$} & \multicolumn{3}{|c|}{ Coordinates $(\AA)$} \\
\hline & $X$ & $Y$ & $Z$ & & $X$ & $Y$ & $Z$ \\
\hline 9 & 9.440787 & 1.399389 & 2.340155 & 6 & -3.909232 & 0.044504 & 0.720625 \\
\hline 9 & 8.737569 & -0.789105 & 2.203095 & 6 & 0.751049 & 1.443980 & 0.492331 \\
\hline 9 & 7.212450 & 0.915910 & 1.959596 & 1 & 0.861093 & 1.760344 & -0.547915 \\
\hline 9 & 8.784661 & 0.541873 & 0.320471 & 1 & 0.335576 & 2.296830 & 1.030378 \\
\hline 5 & 8.545836 & 0.519441 & 1.716432 & 6 & -12.888732 & 0.693264 & 1.120784 \\
\hline 8 & -2.595559 & -0.273336 & 0.629598 & 6 & 6.230795 & -1.198356 & -0.138091 \\
\hline 8 & -14.710088 & 2.095611 & 1.394447 & 1 & 6.773531 & -0.289309 & 0.044622 \\
\hline 8 & -15.091307 & -0.013176 & 1.135774 & 6 & 6.618939 & -2.351744 & -0.738007 \\
\hline 7 & 4.924432 & -1.369976 & 0.270655 & 1 & 7.555788 & -2.628013 & -1.183643 \\
\hline 7 & 5.541127 & -3.210209 & -0.693622 & 6 & -6.660345 & 0.518461 & 0.861868 \\
\hline 7 & -8.022668 & 0.854060 & 0.913226 & 6 & 2.119496 & 1.115267 & 1.088261 \\
\hline 7 & -8.815942 & -0.120927 & 0.863406 & 1 & 2.731825 & 2.020678 & 1.121757 \\
\hline 7 & -14.324590 & 0.946825 & 1.218134 & 1 & 1.978614 & 0.786604 & 2.121138 \\
\hline 6 & -5.760559 & 1.581961 & 0.757719 & 6 & -12.453132 & -0.567560 & 0.722681 \\
\hline 1 & -6.139615 & 2.591510 & 0.694383 & 1 & -13.171752 & -1.321386 & 0.440771 \\
\hline 6 & -10.183810 & 0.221061 & 0.956617 & 6 & -1.655014 & 0.817900 & 0.662038 \\
\hline 6 & -10.647142 & 1.487226 & 1.337628 & 1 & -1.795907 & 1.374067 & 1.592977 \\
\hline 1 & -9.945887 & 2.276527 & 1.559889 & 1 & -1.857625 & 1.499686 & -0.163750 \\
\hline 6 & -6.161806 & -0.794689 & 0.922667 & 6 & -11.090162 & -0.806792 & 0.655971 \\
\hline 1 & -6.859465 & -1.611599 & 1.020889 & 1 & -10.714862 & -1.775276 & 0.349340 \\
\hline 6 & -12.006085 & 1.724757 & 1.428348 & 6 & -0.245636 & 0.277026 & 0.569432 \\
\hline 1 & -12.374440 & 2.682659 & 1.759180 & 1 & -0.162725 & -0.370581 & -0.306726 \\
\hline 6 & -4.393815 & 1.356976 & 0.700786 & 1 & -0.026030 & -0.336757 & 1.442427 \\
\hline 1 & -3.728126 & 2.197949 & 0.622281 & 6 & 4.128295 & -0.372245 & 1.012936 \\
\hline 6 & 4.518993 & -2.593624 & -0.086597 & 1 & 4.792640 & 0.476960 & 1.170376 \\
\hline 1 & 3.552599 & -3.021689 & 0.102030 & 1 & 3.875524 & -0.804487 & 1.978118 \\
\hline 6 & 2.857466 & 0.042465 & 0.291564 & 6 & 5.550515 & -4.592121 & -1.178750 \\
\hline 1 & 2.222515 & -0.835673 & 0.166150 & 1 & 6.176465 & -5.197218 & -0.523817 \\
\hline 1 & 3.105778 & 0.425288 & -0.696736 & 1 & 5.971845 & -4.612007 & -2.179540 \\
\hline 6 & -4.805980 & -1.031170 & 0.841936 & 1 & 4.531894 & -4.965070 & -1.193534 \\
\hline 1 & -4.419870 & -2.041268 & 0.860379 & & & & \\
\hline
\end{tabular}


Table S3. Atomic Cartesian coordinates of the L-form molecules in $\beta$-Cr was fully optimized using ONIOM with the center and the peripheral molecules at the B3LYP/6-311G** and the HF/6-31G levels, respectively.

\begin{tabular}{|c|c|c|c|c|c|c|c|}
\hline \multirow{2}{*}{$\begin{array}{l}\text { Atomic } \\
\text { Number }\end{array}$} & \multicolumn{3}{|c|}{ Coordinates $(\AA)$} & \multirow{2}{*}{$\begin{array}{l}\text { Atomic } \\
\text { Number }\end{array}$} & \multicolumn{3}{|c|}{ Coordinates $(\AA)$} \\
\hline & $X$ & $Y$ & $Z$ & & $X$ & $Y$ & $Z$ \\
\hline 8 & 2.289247 & 0.333770 & 4.246635 & 6 & 1.294633 & -0.728160 & 4.177747 \\
\hline 8 & 13.607350 & -0.829716 & -0.685397 & 1 & 1.743923 & -1.655605 & 4.534092 \\
\hline 8 & 14.040307 & 1.124452 & 0.127908 & 1 & 1.014014 & -0.866104 & 3.131353 \\
\hline 7 & 7.252022 & -0.293595 & 1.835455 & 6 & 10.268412 & 1.482651 & 1.674132 \\
\hline 7 & 8.085319 & 0.629525 & 2.039723 & 1 & 9.968304 & 2.346064 & 2.246901 \\
\hline 6 & 5.638969 & 1.077930 & 3.122241 & 6 & -2.384203 & 1.854436 & 1.163677 \\
\hline 1 & 6.373864 & 1.861050 & 3.208834 & 1 & -2.696318 & 2.831130 & 0.790598 \\
\hline 7 & 13.275299 & 0.192261 & -0.088702 & 1 & -1.582566 & 1.471318 & 0.537603 \\
\hline 6 & 5.988534 & -0.082732 & 2.407178 & 6 & -3.572757 & -0.161700 & 0.140641 \\
\hline 6 & 11.024404 & -0.774392 & 0.210699 & 1 & -2.743944 & -0.455094 & -0.484245 \\
\hline 1 & 11.338825 & -1.624462 & -0.375807 & 6 & -4.801224 & -0.725593 & 0.301596 \\
\hline 7 & -3.516167 & 0.925249 & 0.986202 & 1 & -5.242838 & -1.591792 & -0.161217 \\
\hline 6 & 11.909859 & 0.281252 & 0.431439 & 6 & -1.922707 & 1.932001 & 2.610231 \\
\hline 6 & 9.362205 & 0.437826 & 1.471070 & 1 & -1.182054 & 2.730262 & 2.623624 \\
\hline 6 & 3.452996 & 0.170966 & 3.583158 & 1 & -2.744153 & 2.258208 & 3.255213 \\
\hline 6 & -1.307891 & 0.634848 & 3.132676 & 6 & -0.723115 & 0.812932 & 4.536345 \\
\hline 1 & -0.522001 & 0.336045 & 2.431826 & 1 & -0.079729 & 1.691164 & 4.547826 \\
\hline 1 & -2.045382 & -0.171005 & 3.150412 & 1 & -1.537634 & 0.999991 & 5.243683 \\
\hline 6 & 11.544469 & 1.416032 & 1.143612 & 6 & 0.099779 & -0.369688 & 5.039910 \\
\hline 1 & 12.236231 & 2.236177 & 1.254285 & 1 & -0.513629 & -1.261309 & 5.111315 \\
\hline 6 & 4.399898 & 1.209382 & 3.701236 & 1 & 0.441554 & -0.162731 & 6.054610 \\
\hline 1 & 4.149198 & 2.091888 & 4.271946 & 6 & -6.846704 & -0.128369 & 1.703468 \\
\hline 7 & -5.463897 & 0.025499 & 1.252275 & 1 & -6.872807 & -0.049692 & 2.787233 \\
\hline 6 & 5.030829 & -1.083654 & 2.243562 & 1 & -7.225490 & -1.094903 & 1.386876 \\
\hline 1 & 5.266904 & -1.965892 & 1.664811 & 1 & -7.452022 & 0.650563 & 1.265240 \\
\hline 6 & 3.771812 & -0.952586 & 2.816427 & 5 & -2.439484 & -1.666796 & -3.007195 \\
\hline 1 & 3.057537 & -1.743820 & 2.695480 & 9 & -2.896258 & -0.611893 & -3.847654 \\
\hline 6 & -4.665091 & 1.014859 & 1.655527 & 9 & -3.551576 & -2.264665 & -2.362742 \\
\hline 1 & -4.903409 & 1.731361 & 2.423513 & 9 & -1.540309 & -1.179266 & -2.054705 \\
\hline 6 & 9.749275 & -0.689829 & 0.732724 & 9 & -1.828691 & -2.621692 & -3.831787 \\
\hline 1 & 9.029193 & -1.477634 & 0.577397 & & & & \\
\hline
\end{tabular}


Table S4. Energy calculation results. The rows a-f indicate the energies obtained for various molecular systems and under various computational conditions: a, b) 1-Bf ion pair at the center of the cluster at the HF/6-31G and B3LYP/6-311G** levels, respectively; c, d) 18-molecule cluster of 1-Bf at the HF/6-31G level, and extrapolation to B3LYP/6-311G** level under ONIOM scheme, respectively; e, f) cation and anion part, respectively, picked up from the central moiety of the cluster at the B3LYP/6-311G** level. Energies for a-d were those given in the output files of ONIOM calculation.

\begin{tabular}{ccccc}
\hline & $E_{\mathrm{L}}$ & $E_{\mathrm{SS}}$ & $E_{\mathrm{L}}-E_{\mathrm{SS}}$ & Molecular system \\
& $/$ a.u. & $/$ a.u. & $\mathrm{kJ} \mathrm{mol}^{-1}$ & \\
\hline $\mathrm{a}$ & -1766.858628 & -1766.854102 & -11.88 & center (ion pair) \\
$\mathrm{b}$ & -1778.178385 & -1778.171953 & -16.89 & center (ion pair) \\
$\mathrm{c}$ & -31804.183840 & -31803.700560 & -1268.85 & cluster \\
$\mathrm{d}$ & -31815.503600 & -31815.018400 & -1273.89 & cluster \\
$\mathrm{e}$ & -1353.407816 & -1353.407652 & -0.43 & center (cation) \\
$\mathrm{f}$ & -424.647250 & -424.646869 & -1.00 & center (anion) \\
\hline
\end{tabular}

$E_{\mathrm{L}}, E_{\mathrm{SS}}$ are the calculated energy of the structure (molecule or cluster) in the L-form and SS-form, respectively.

The quantum chemical calculations indicate that the ion pair in the L-form in $\alpha-\mathrm{Cr}$ is more stable than the ion pair in the SS-form in $\beta$-Cr by $16.9 \mathrm{~kJ} \mathrm{~mol}^{-1}$ (Table S4, row b). This energy includes the energy of the conformational change of the molecule and the energy of the Coulomb interaction with neighboring molecules. The energy of the change in molecular conformation alone was estimated to be $1.43 \mathrm{~kJ} \mathrm{~mol}^{-1}$ (Table S4, row e+f), which is smaller than the thermal energy at around room temperature $\left[\approx 2.3-2.5 \mathrm{~kJ} \mathrm{~mol}^{-1}\right]$. Therefore, we attribute the remaining energy difference of $15.5 \mathrm{~kJ} \mathrm{~mol}^{-1}$ to the Coulomb interaction energy. 